\title{
CORRELATION BETWEEN AORTIC ROOT STIFFNESS AND AORTIC ROOT 2D SPECKLE STRAIN IN PATIENTS HAVING CORONARY ARTERY DISEASE
}

\author{
By \\ Ahmed Hamdy Abd El-Aziz**, Abou-Bakr El-Seddik Tammam \\ Hussein* and Al-Hussein Mustafa Zahran \\ *Cardiology Department, Faculty of Medicine, Al-Azhar University, Cairo, Egypt \\ **Corresponding author: Ahmed Hamdy Abd El-Aziz, \\ Mobile: 01015218546, E-mail: ahm.ham.bay@gmail.com
}

\begin{abstract}
Background: Aortic stiffness is a hallmark of aging, and classic cardiovascular risk factors play a role in accelerating this process. Current changes in medicine, which focus on preventive care, have led to an interest in noninvasive evaluation of aortic stiffness. Aortic stiffness has emerged as a good tool for further risk stratification because it has been linked to increased risk of atherosclerotic heart disease, myocardial infarction and heart failure.
\end{abstract}

Objective: To assess feasibility of aortic root 2D-ST echocardiography for the early prediction of ischemic heart patients and its correlation with aortic stiffness parameters.

Patients and Methods: Seventy patients were included in this study which further subdivided into 45 ischemic patients (ischemic group) and 25 non ischemic patients (normal group). Informed consent, detailed history, physical examination, resting 12 leads ECG, full laboratory investigations, conventional 2D echocardiography, aortic root 2D-ST echocardiography and coronary angiography were done. The study was performed at Bab Al-Sharia University Hospital during the period from April 2020 to October 2020.

Results: Global circumferential ascending aortic root strain (CAAS) and longitudinal ascending aortic root strain (LAAS) significantly decreased with the presence of significant coronary stenosis, both of them decreased incrementally with increasing severity of CAD, and there was significant correlation between aortic root 2D strain parameters and aortic stiffness parameters.

Conclusion: Global circumferential ascending aortic root strain and longitudinal ascending aortic root strain assessed by aortic root 2D-ST echocardiography at rest were an independent predictor of significant CAD. Furthermore, global CAAS and LAAS were related to the severity of CAD and capable of identifying multivessel disease.

Keywords: Global circumferential ascending aortic root strain, longitudinal ascending aortic root strain, aortic stiffness index, aortic distensibility, aortic root 2D speckle tacking echocardiography.

\section{INTRODUCTION}

Arterial stiffening is one of the earliest detectable manifestations of adverse structural and functional changes within the vessel wall. Degenerative stiffening of the arterial beds i.e., arteriosclerosis tends to coexist, causing progressive, diffuse, and age-related deterioration in all vascular beds (Cavalcante et al., 2011). 
Increased aortic stiffness is a risk factor for cardiovascular diseases and a predictor of cardiovascular morbidity and mortality. Consequently, assessment of arterial stiffness is increasingly used in clinical practice. However, validity and reproducibility of the conventional methods used for local assessment of arterial stiffness, such as elastic modulus, distensibility, and stiffness index, are limited by their dependence on the patient's blood pressure (Kim et al., 2012).

Two-dimensional speckle tracking echocardiography is a promising new imaging modality. It permits offline assessment of tissue velocities and deformation parameters such as strain and strain rate. It is well accepted that these parameters provide important insights into systolic and diastolic function, myocardial mechanics and many other pathophysiological processes of the heart (Yuda et al., 2011).

Two-dimensional

(2D) strain echocardiography was developed to allow a rapid, accurate, angle-independent determination of regional myocardial deformation (Bu et al., 2018).

Circumferential deformation of the descending thoracic aorta, abdominal aorta, or carotid arteries can be measured using 2D speckle tracking (2D-ST), allowing a simple and accurate determination of aortic stiffness (Teixeira et al., 2015).

The development and progression of atherosclerosis is important, especially in cardiovascular diseases. Atherosclerosis decreases the flexibility of large vessels and the vascular bed, and the decreased flexibility facilitates atherosclerotic development. Currently, it is possible to measure the flexibility change (aortic stiffness index and distensibility) by noninvasive echocardiography (Şatiroğlu et al., 2012).

Aorta influences the circulation in a global fashion by serving as a conduit and playing important roles in modulating left ventricular (LV) performance, myocardial perfusion, central hemodynamics, and arterial function throughout the entire cardiovascular system (Boudoulas et al., 2012).

The elastic properties of the aorta can be related to the degree of CAD. Hence, it would be appealing if the ascending aortic strain assessed by 2D-ST echocardiography could improve the diagnostics for coronary artery stenosis (Bu et al., 2018).

The aim of this work was to assess feasibility of real-time two-dimensional speckle tracking echocardiography on the aortic root for the early prediction of ischemic heart patients and its correlation with aortic stiffness parameters.

\section{PATIENTS AND METHODS}

This pilot study involved patients with acute myocardial infarction (STEMI, nonSTEMI and unstable angina) and patients with stable anginal pain, the patients were screened for the study enrolment prospectively. The study was performed at Bab Al-Sharia Hospital, Al-Azhar University, during the period from April 2020 to October 2020. The protocol and all corresponding documents were approved by Ethical and Research committee, Faculty of Medicine, Al-Azhar University and patients provided informed consents. 
The patients were classified into two groups matched in age:

Group (1): Patients group: 45 patients (50-75 years old) with acute coronary syndrome or patients with stable anginal pain.

Group (2): Control group 25 patients (same age group) with similar demographic characteristics but with normal coronary angiography.

Inclusion criteria: All patients with acute coronary syndrome (STEMI, non-STEMI and unstable angina) and stable anginal pain.

Exclusion criteria: Patients with impaired LV systolic function ( $\mathrm{EF}<50 \%)$, patients with significant valvular heart disease, myocardial and pericardial disease, congenital heart disease, left ventricular hypertrophy, chronic systemic or inflammatory diseases, any form of malignancy, aortic aneurysms, systematic diseases affecting the aorta, arrhythmias and intraventricular conduction disturbances.

All subjects were exposed to full history taking, general and local cardiac examination, resting 12-lead ECG, resting conventional echocardiography, aortic root 2D-ST echocardiograph and coronary angiography.

Gensini score was used to assess the severity of epicardial coronary artery disease (Kobayashi, et al., 2017).
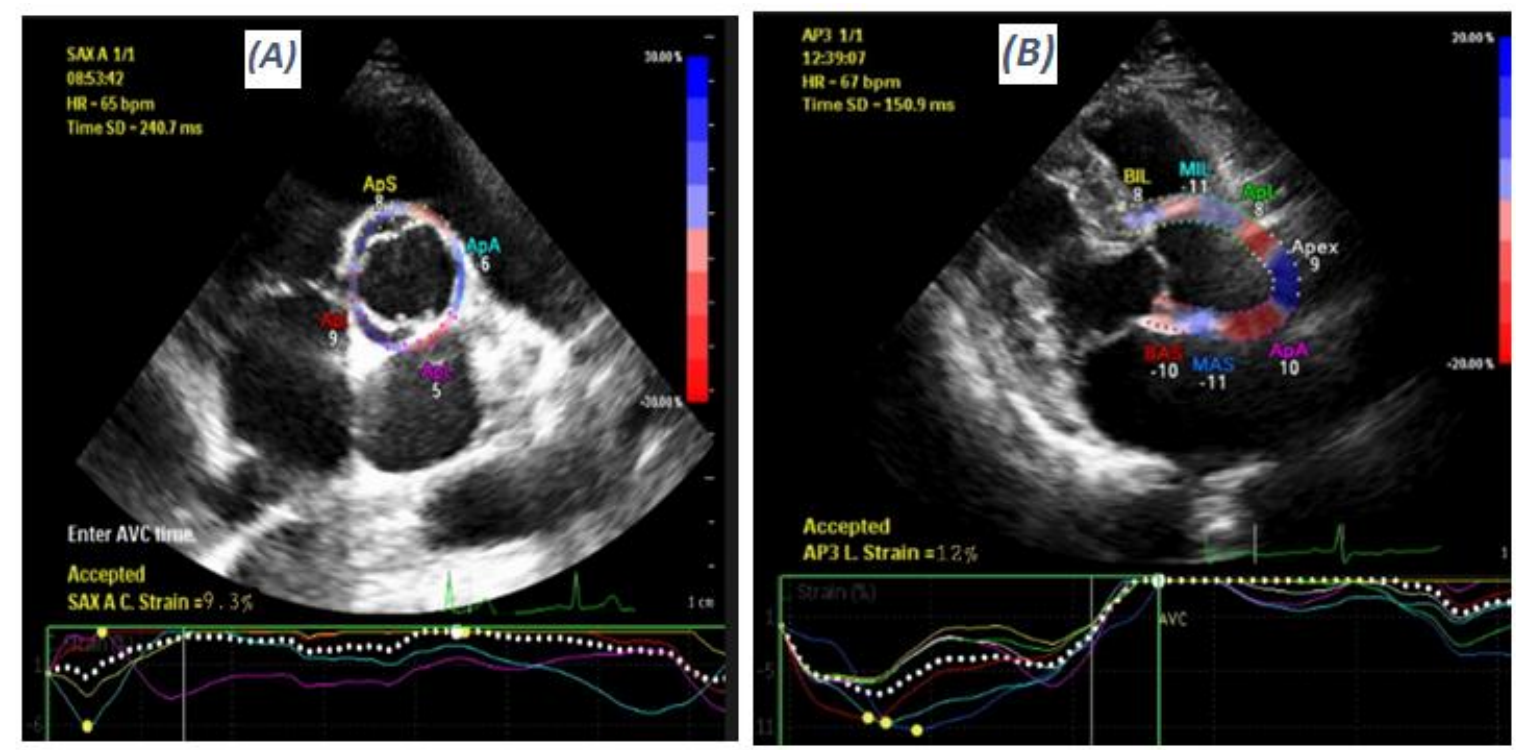

Figure (1): (A) Representative CAAS curves in a patient without significant coronary stenosis. Peak values of CAAS in each color-coded curve were measured, and then the global CAAS was calculated as the mean of 6 peak values. This patient had a global CAAS of 9.3\% . (B) Representative LAAS curves in a patient with significant coronary stenosis. This patient had a global LAAS of $12 \%$ 


\section{Statistical analysis:}

Data were tabulated and analyzed using the computer programme SPSS (Statistical package for the social sciences) version 20.0 (SPSS Inc., Chicago, Illinois, USA). Quantitative data were expressed as mean \pm standard deviation (SD) and range. Qualitative data were expressed as frequency and percentage.

\section{The following tests were done:}

- Independent-samples t-test of significance was used when comparing between two means.

- A one-way analysis of variance (ANOVA) when comparing between more than two means.

- Post Hoc test: Least Significant Difference (LSD) was used for multiple comparisons between different variables.
- Mann Whitney U test for two-group comparisons in non-parametric data.

- Chi-square (x2) test of significance was used in order to compare proportions between qualitative parameters.

- Pearson's correlation coefficient (r) test was used to assess the degree of association between two sets of variables.

- Scatter plot: A graph in which the values of two variables are plotted along two axes, the pattern of the resulting points revealing correlation present.

- Receiver operating characteristic (ROC curve) analysis was used to find out the overall predictively of parameter and to find out the best cut-off value with detection of sensitivity and specificity at this cut-off value.

\section{RESULTS}

The study included 49 males and 21 females. The mean age was $60.69 \pm 5.8$ years. Age ranged from 50 years to 73 years. There was a statistically significant difference between both groups regarding diabetic history. Patients were $57.8 \%$ diabetic, while control were $32 \%$ $(\mathrm{p}=0.039)$. On the other hand, there was no statistically significant difference between both groups as regarding other risk factors including hypertension, smoking and dyslipidemia. Patients were $55.6 \%$ hypertensive $(\mathrm{p}=0.544), \quad 48.9 \%$ smokers $(\mathrm{p}=0.474)$, and $35.6 \%$ with dyslipidemia $(\mathrm{p}=0.318)$, while control were $48 \%$ hypertensive, $40 \%$ smokers and $24 \%$ with dyslipidemia.

There was no statistically significant difference between both groups according to systolic $(\mathrm{p}=0.165)$ and diastolic $(\mathrm{p}=0.122)$ blood pressure (Table 1).

There was a statistically significant difference between both groups according to LAD ( $p=0.039), \operatorname{LVESD}(\mathrm{p}=0.041)$ and LV EF\% ( $\mathrm{p}=0.006)$ but there was no statistically significant difference according to others (Table 2). 
( Table 1): Comparison between patients and control according to blood pressure

\begin{tabular}{|c|c|c|c|}
\hline $\begin{array}{ll}\text { Blood pressure } & \text { Groups } \\
\end{array}$ & Patients $(n=45)$ & Control $(n=25)$ & p-value \\
\hline \multicolumn{4}{|l|}{ Systolic (mmHg) } \\
\hline Mean \pm SD & $137.56 \pm 18.88$ & $130.80 \pm 20.04$ & \multirow{2}{*}{0.165} \\
\hline Range & $100-170$ & $110-180$ & \\
\hline \multicolumn{4}{|l|}{ Diastolic (mmHg) } \\
\hline Mean \pm SD & $89.11 \pm 13.41$ & $83.80 \pm 13.94$ & \multirow{2}{*}{0.122} \\
\hline Range & $60-110$ & $60-100$ & \\
\hline
\end{tabular}

Using: Independent Sample t-test

(Table 2): Comparison between patients and control according to echo parameters

\begin{tabular}{|c|c|c|c|}
\hline $\begin{array}{l}\text { Groups } \\
\text { Echo parameters }\end{array}$ & Patients $(n=45)$ & Control $(n=25)$ & p-value \\
\hline \multicolumn{4}{|l|}{ LAD $(\mathbf{c m})$} \\
\hline Mean \pm SD & $3.84 \pm 0.55$ & $3.61 \pm 0.38$ & \multirow[b]{2}{*}{0.068} \\
\hline Range & $2.8-4.7$ & $2.9-4.3$ & \\
\hline \multicolumn{4}{|l|}{ ADD (cm) } \\
\hline Mean \pm SD & $3.07 \pm 0.41$ & $2.96 \pm 0.39$ & \multirow{2}{*}{0.278} \\
\hline Range & $1.9-4.1$ & $2.2-3.6$ & \\
\hline \multicolumn{4}{|l|}{ ASD (cm) } \\
\hline Mean \pm SD & $3.25 \pm 0.43$ & $3.28 \pm 0.39$ & \multirow{2}{*}{0.774} \\
\hline Range & $2-4.24$ & $2.5-3.9$ & \\
\hline \multicolumn{4}{|l|}{ LVEDD (cm) } \\
\hline Mean \pm SD & $4.88 \pm 0.60$ & $4.94 \pm 0.45$ & \multirow{2}{*}{0.666} \\
\hline Range & $3.42-6.1$ & $3.97-5.45$ & \\
\hline \multicolumn{4}{|l|}{ LVESD $(\mathrm{cm})$} \\
\hline Mean \pm SD & $3.43 \pm 0.39$ & $3.20 \pm 0.76$ & \multirow{2}{*}{0.098} \\
\hline Range & $2.5-4.4$ & $0-3.9$ & \\
\hline \multicolumn{4}{|l|}{ LV EF (\%) } \\
\hline Mean \pm SD & $58.38 \pm 5.77$ & $62.30 \pm 4.12$ & \multirow{2}{*}{0.004} \\
\hline Range & $36-71$ & $55-71$ & \\
\hline
\end{tabular}

Using: Independent Sample t-test

There was a statistically significant difference between both groups regarding longitudinal and circumferential aortic root strain $(\mathrm{P}<0.001)$ (Table 3$)$.
There was a statistically significant difference between both groups according to aortic stiffness index $(\mathrm{P}<0.001)$ (Table 4). 
(Table 3): Comparison between patients and control according to strain values

\begin{tabular}{|c|c|c|c|}
\hline Speckle tracking $\quad$ Groups & $\begin{array}{l}\text { Patients } \\
(n=45)\end{array}$ & $\begin{array}{c}\text { Control } \\
(n=25)\end{array}$ & p-value \\
\hline \multicolumn{4}{|l|}{$\begin{array}{l}\text { Longitudinal Aortic root } \\
\text { strain }\end{array}$} \\
\hline Mean \pm SD & $9.10 \pm 2.05$ & $13.63 \pm 2.25$ & \multirow[b]{2}{*}{$<0.001$} \\
\hline Range & $5.9-13$ & $8-17$ & \\
\hline \multicolumn{4}{|l|}{$\begin{array}{l}\text { Circumferential Aortic root } \\
\text { strain }\end{array}$} \\
\hline Mean \pm SD & $6.22 \pm 1.97$ & $11.82 \pm 1.95$ & \multirow{2}{*}{$<0.001$} \\
\hline Range & $3.2-9.55$ & $8.5-15$ & \\
\hline
\end{tabular}

Using: Independent Sample t-test

(Table 4): Comparison between patients and control according to aortic stiffness index

\begin{tabular}{|c|c|c|c|}
\hline $\begin{array}{ll}\text { Aortic stiffness index } & \text { Groups } \\
\end{array}$ & Patients $(n=45)$ & Control $(n=25)$ & p-value \\
\hline Mean \pm SD & $7.69 \pm 1.71$ & $4.98 \pm 2.41$ & \multirow{2}{*}{$<0.001$} \\
\hline Range & $4.21-10.86$ & $1.77-10.61$ & \\
\hline
\end{tabular}

Using: Mann-Whitney test

Global CAAS decreased incrementally with increasing severity of CAD as determined by an increasing number of coronary vessels with lumen area stenosis $\geq 70 \%$. In patients having no CAD or 1,2 , and 3 vessel disease $(\mathrm{P}<0.001)$ (Table 5).

Table (5): Relation between number of vessels affected with longitudinal and circumferential aortic root strain in patients group

\begin{tabular}{|l|c|c|c|c|}
\hline \multirow{2}{*}{ Gpeckle tracking } & \multicolumn{3}{|c|}{ Number of vessels affected } & \multirow{2}{*}{ ANOVA } \\
\cline { 2 - 5 } & $\begin{array}{c}\text { 1 vessel } \\
(\mathbf{1 1})\end{array}$ & $\begin{array}{c}\mathbf{2} \text { vessels } \\
(\mathbf{1 8})\end{array}$ & $\begin{array}{c}\text { 3 vessels } \\
(\mathbf{1 6})\end{array}$ & \multirow{2}{*}{-value } \\
\hline Longitudinal aortic root strain & & & & \\
\hline Mean \pm SD & $11.70 \pm 0.69$ & $9.49 \pm 0.99 \mathrm{a}$ & $6.87 \pm 0.66 \mathrm{ab}$ & \multirow{2}{*}{$<0.001$} \\
\hline Range & $10.39-13$ & $7.99-11.65$ & $5.9-8.21$ & \\
\hline $\begin{array}{l}\text { Circumferential aortic root } \\
\text { strain }\end{array}$ & & & & \\
\hline Mean \pm SD & $8.90 \pm 0.64$ & $6.42 \pm 0.75 \mathrm{a}$ & $4.16 \pm 0.77 \mathrm{ab}$ & \multirow{2}{*}{$<0.001$} \\
\hline Range & $7.8-9.55$ & $5.3-8$ & $3.2-5.8$ & \\
\hline
\end{tabular}

Using: One Way Analysis of Variance: Post HOC test: a: significant difference with 1 vessel; b: significant difference with 2 vessels

There was a positive correlation between longitudinal ascending aortic root strain with circumferential ascending aortic root strain $(\mathrm{P}<0.001)$, and aortic distensibility $(\mathrm{P}<0.001)$. There was a negative correlation between longitudinal aortic root strain with aortic stiffness index $(\mathrm{P}<0.001)$, hypertension $(\mathrm{P}=0.004)$, systolic $(\mathrm{P}<0.001)$ and diastolic $(\mathrm{P}<$ $0.001)$ blood pressure, number of vessels affected $(\mathrm{P}<0.001)$ and left atrial diameter $(\mathrm{P}=0.002)$ (Figure 2). 


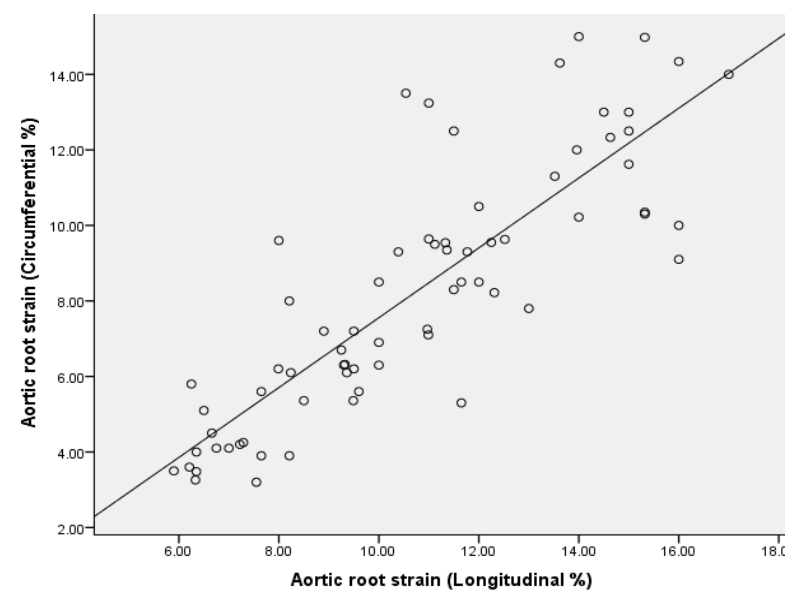

(Figure 2):Scatter plot between circumferential and longitudinal aortic root strain

Also, there was a positive correlation between circumferential aortic root strain with aortic distensibility $(\mathrm{P}<0.001)$. While there was a negative correlation between circumferential aortic root strain with aortic stiffness index $(\mathrm{P}<0.001)$, hypertension $\quad(\mathrm{P}=0.004)$, systolic $\quad(\mathrm{P}<$ $0.001)$ and diastolic $(\mathrm{P}<0.001)$ blood pressure, number of vessels affected $(\mathrm{P}<$ $0.001)$ and left atrial diameter $(\mathrm{p}=0.002)$ (Figure 3).

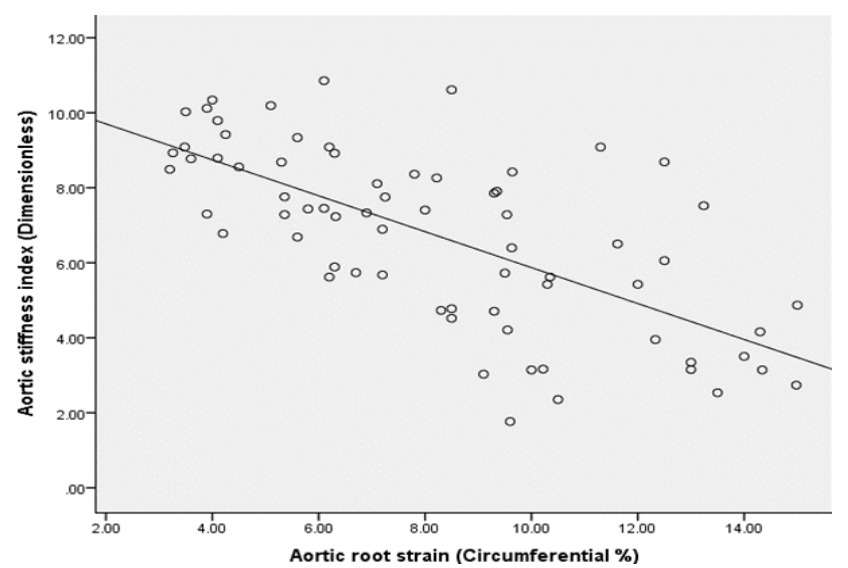

(Figure 3):Scatter plot between circumferential aortic root strain and aortic stiffness index

There was a positive correlation between aortic stiffness index with diabetes $(\mathrm{P}<0.005)$, hypertension $(\mathrm{P}<$ $0.001)$, waist circumference $(p=0.037)$, dyslipidemia $(\mathrm{p}=0.0$ 97), systolic $(\mathrm{P}<$ $0.001)$ and diastolic blood pressure $(\mathrm{P}<$ $0.001)$, number of vessels affected $(\mathrm{P}<$ $0.001)$ and left atrial diameter $(\mathrm{P}<0.001)$ while there was a negative correlation between aortic stiffness index with aortic distensibility $(\mathrm{P}<0.001)$. Also, there was a negative correlation between aortic distensibility with diabetes $(\mathrm{p}=0.012)$, hypertension $\quad(\mathrm{P}<0.001), \quad$ waist circumference $\quad(\mathrm{p}=0.046), \quad$ systolic $(\mathrm{P}<$ 0.001) and diastolic $(\mathrm{P}<0.001)$ blood pressure, number of vessels affected $(\mathrm{P}<$ $0.001)$, and left atrial diameter $(\mathrm{P}<0.001)$.

Receiver operating characteristic curve found the cut-off value for prediction of ischemic heart disease (Figure 4 and Table 6). 

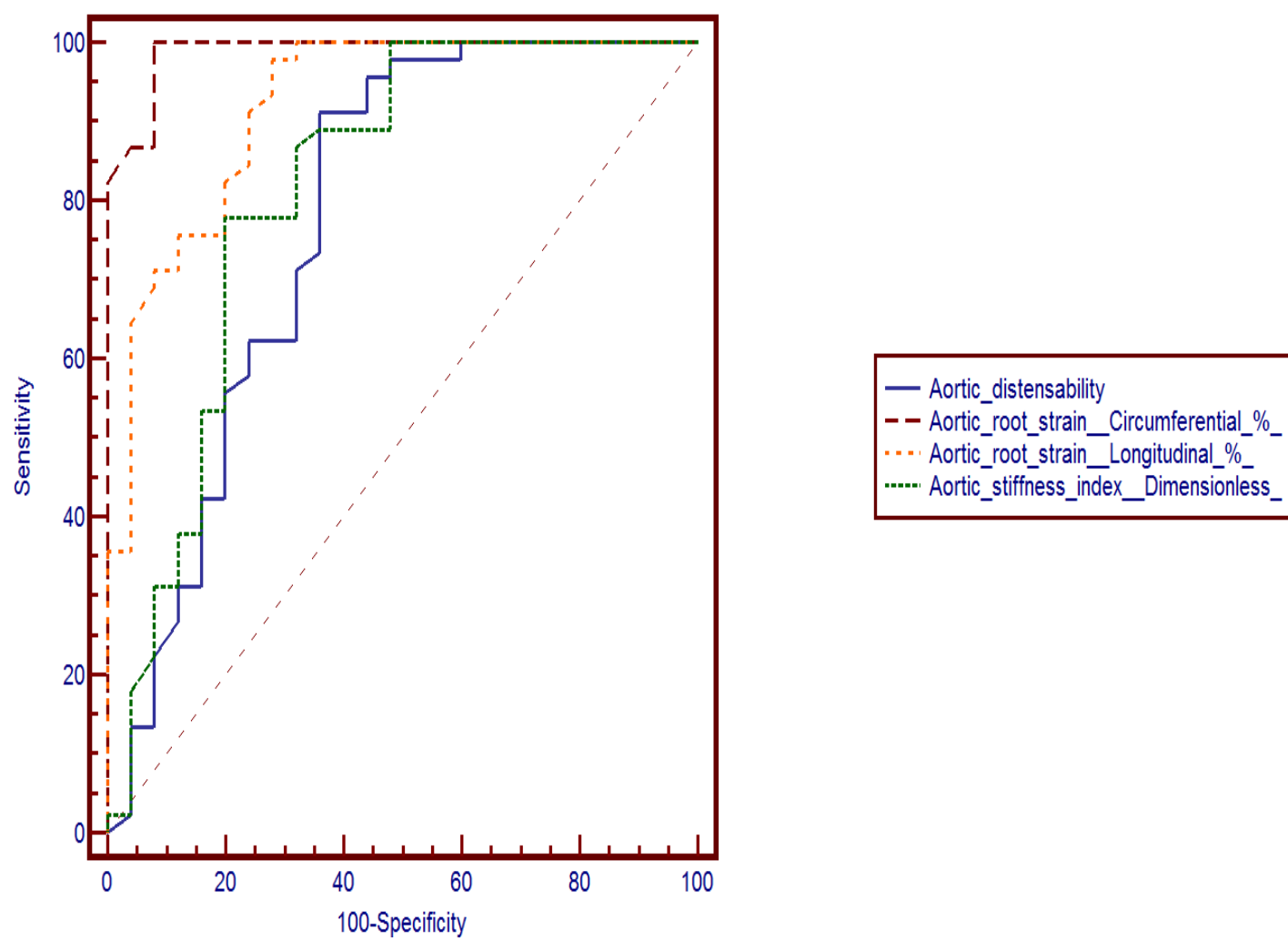

(Figure 4): Receiver-operating characteristic (ROC) curve for prediction of ischemic heart disease using longitudinal aortic root strain, circumferential aortic root strain, aortic stiffness index and aortic distensibility

Table (6): Cut-off value for prediction of ischemic heart disease

\begin{tabular}{|l|c|c|c|c|c|c|}
\hline Items & Cut-off & Sen. & Spec. & PPV & NPV & Accuracy \\
\hline Longitudinal aortic root strain & $\leq 11.5$ & $84.4 \%$ & $76 \%$ & $86.4 \%$ & $73.1 \%$ & $85.9 \%$ \\
\hline $\begin{array}{l}\text { Circumferential aortic root } \\
\text { strain }\end{array}$ & $\leq 9.1$ & $96.7 \%$ & $92 \%$ & $95.1 \%$ & $79.3 \%$ & $98.8 \%$ \\
\hline Aortic stiffness index & $\geq 6.5$ & $77.8 \%$ & $80 \%$ & $87.5 \%$ & $66.7 \%$ & $81.3 \%$ \\
\hline Aortic distensibility & $\leq 3.03$ & $73.3 \%$ & $64 \%$ & $78.6 \%$ & $57.1 \%$ & $77.5 \%$ \\
\hline
\end{tabular}

\section{DISCUSSION}

Regarding $2 \mathrm{D}$ conventional echocardiographic parameters, there was a statistically significant difference between both groups according to LV EF\% and this in agreement with Şatiroğlu et al. (2012), Güngör et al. (2014) and Bu et al. (2018).

There was no statistically significant difference according to other parameters i.e., LAD, ASD, ADD, LVESD and LVEDD. This was consistent with $\mathrm{Bu}$ et al. (2018), but against Şatiroğlu et al. (2012) and Güngör et al. (2014) which can be explained by the same prevalence of hypertension and age in both groups which significantly affect aortic diameters.

Regarding 2D-ST echo parameters, there were statistically significant differences between both groups regarding longitudinal and circumferential aortic root strain. 
The global CAAS assessed by 2D-ST echocardiography at rest was significantly lower in patients with significant CAD than in patients without CAD which was in agreement with Bu et al. (2018).

The global LAAS assessed by 2D-ST echocardiography at rest was significantly lower in patients with significant CAD than in patients without CAD .

Regarding aortic stiffness index and aortic distensibility. There was high statistically significant difference between both groups according to aortic stiffness index and aortic distensibility, which were consistent with Şatiroğlu et al. (2012), Güngör et al. (2014), Bu et al. (2018), Ahmed et al. (2019) and Lфnnebakken et al. (2019) and El-Naggar et al. (2020).

In this current study, the global CAAS obtained by 2D-ST echocardiography had a high feasibility and satisfactory reproducibility, global CAAS at rest predict significant $\mathrm{CAD}$ with high sensitivity (96\%) in patients with CAD, and this was consistent with $\mathrm{Bu}$ et al. (2018) who concluded the same results, but with sensitivity of $86 \%$.

Based on the ROC curve of the global CAAS for diagnosing significant CAD, the area under the ROC curve was significantly large, and the optimal cut-off value of global CAAS was $9.1 \%$. The ability of global CAAS to differentiate significant $\mathrm{CAD}$ was remarkable, with 92\% of enrolled patients with global CAAS $\leq 9.1 \%$ having significant coronary stenosis confirmed by coronary angiography. According to the data from this study, global CAAS had a high accuracy to predict significant CAD, rendering it a potential marker for $\mathrm{CAD}$, compared to LAAS with area under the
ROC curve smaller than that of global CAAS with optimal cut-off value was $11.5 \%$ with $76 \%$ of enrolled patients with global LAAS $\leq 11.5 \%$ having significant coronary stenosis confirmed by coronary angiography. Also, the optimal cut of value of aortic stiffness index was 6.5 with $80 \%$ of enrolled patients with aortic stiffness index $\geq 6.5$ having significant coronary stenosis. Global CAAS was considered the most significant predictor of CAD, and this finding was consistent with $\mathrm{Bu}$ et al. (2018).

This study demonstrated that both global CAAS and LAAS decreased incrementally with increasing severity of $\mathrm{CAD}$, as determined by an increasing number of diseased vessels. Further analysis showed that global CAAS had a significant association with 3-Vessele Disease and was able to detect or exclude multivessel CAD with a satisfactory diagnostic performance (sensitivity $96.7 \%$, specificity $92 \%$ ), compared to the study of Bu et al. (2018) with sensitivity $86 \%$ and specificity $70 \%$.

Global CAAS decreased incrementally with increasing severity of CAD as determined by an increasing number of coronary arteries with lumen area stenosis $\geq 70 \%$. Accordingly, global CAAS and LAAS can be used as a predictor of severity of coronary artery disease and this correlated with Bu et al. (2018).

\section{CONCLUSION}

Global circumferential ascending aortic root strain and longitudinal ascending aortic root strain assessed by 2D-ST echocardiography at rest were an independent predictor of significant CAD. Also, global CAAS and LAAS were related to the severity of CAD and capable 
of identifying multivessel disease; aortic stiffness index and distensibility were an old method used for a local assessment of arterial stiffness. However, validity and reproducibility of these methods are limited because of their dependence on the patient's blood pressure and now can be replaced by new strain methods.

\section{REFERENCES}

1. Ahmed, M., Adam, K. and ElShafey, W. (2019): Assessment of Aortic Root Mechanics in Hypertensive Patients by Speckle Tracking Echocardiography. World Journal of Cardiovascular Diseases, 9: 212-222.

2. Bieseviciene, M., Vaskelyte, J., Mizariene, V., Karaliute, R., Lesauskaite, V. and Verseckaite, $\mathbf{R}$. (2017): Two-dimensional speckletracking echocardiography for evaluation of dilative ascending aorta biomechanics. Bio Medical Center, 17: 27-35.

3. Boudoulas, K., Vlachopoulos, C., Raman, S., Sparks, E., Triposciadis, F., Stefanadis, C. and Boudoulas, H. (2012): Aortic function: from the research laboratory to the clinic. Cardiology, 121: 31-42.

4. Bu, Z., Ma, J., Fan, Y., Qiao, Z., Kang, Y., Zheng, Y., Wang, W., Du, Y., Zheng, Z., Shen, X. and He, B. (2018): Ascending Aortic Strain Analysis Using 2-Dimensional Speckle Tracking Echocardiography Improves the Diagnostics for Coronary Artery Stenosis in Patients with Suspected Stable Angina Pectoris. Journal of the American Heart Association, 7: 8802-8850.
5. Cavalcante, J., Lima, J., Redheuil, A. and Al-Mallah, M. (2011): Aortic stiffness: current understanding and future directions. Journal of the American College of Cardiology, 57: 1511-1522.

6. El-Naggar, H., Anwar, H., Helmy, H. and Demitry, S. (2020): Aortic root distensibility and stiffness assessed by echocardiography as predictors of coronary artery lesion severity in patients undergoing coronary angiography. European Heart Journal-Cardiovascular Imaging, 21: 319-927.

7. Güngör, B., Yılmaz, H., Ekmekçi, A., Özcan, K., Tijani, M., Osmonov, D., Karataş, B., Alper, A., Mutluer, F., Gürkan, U. and Bolca, O. (2014): Aortic stiffness is increased in patients with premature coronary artery disease: a tissue Doppler imaging study. Journal of Cardiology, 63: 223-229.

8. Kim, S., Park, S., Kim, M., Kim, Y., Cho, D., Ahn, C., Hong, S., Lim, D. and Shim, W. (2012): The relationship between mechanical properties of carotid artery and coronary artery disease. European Heart Journal-Cardiovascular Imaging, 13: 568-573.

9. Kobayashi, Y., Lee, J., Fearon, W., Lee, J., Nishi, T., Choi, D. and Nam, C. (2017): Three-vessel assessment of coronary microvascular dysfunction in patients with clinical suspicion of ischemia: prospective observational study with the index of microcirculatory resistance. Circulation: Cardiovascular Interventions, 10: 54-60. 
10. Lønnebakken, M., Eskerud, I., Larsen, T., Midtbø, H., Kokorina, M. and Gerdts, E. (2019): Impact of aortic stiffness on myocardial ischaemia in non-obstructive coronary artery disease. Open Heart, 6: 981-999.

11. Şatiroğlu, Ö., Bostan, M., Bayar, N., Çiçek, Y., Cetin, M. and Bozkurt, E. (2012): Relation between aortic stiffness and extension of coronary artery disease. Turkish Journal of Medical Sciences, 42: 417424.

12. Teixeira, R., Monteiro, R., Baptista, R., Barbosa, A., Leite, L., Ribeiro, M., Martins, R., Cardim, N. and Gonçalves, L. (2015):
Circumferential vascular strain rate to estimate vascular load in aortic stenosis: a speckle tracking echocardiography study. The International journal of Cardiovascular Imaging, 31: 681-689.

13. Yuda, S., Kaneko, R., Muranaka, A., Hashimoto, A., Tsuchihashi, K., Miura, T., Watanabe, N. and Shimamoto, K. (2011): Quantitative measurement of circumferential carotid arterial strain by twodimensional speckle tracking imaging in healthy subjects. Echocardiography, 28: 899-906. 


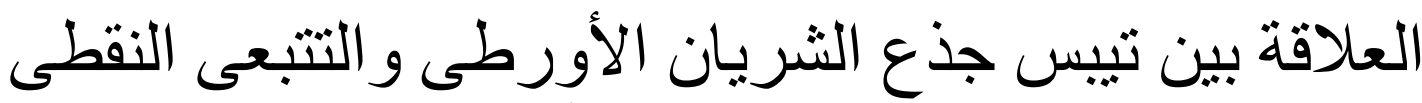

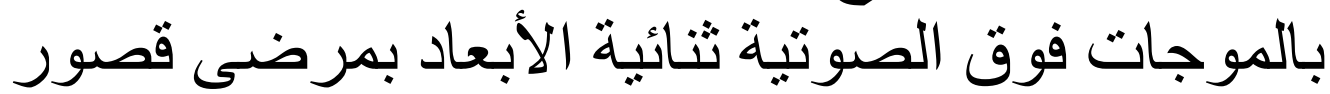

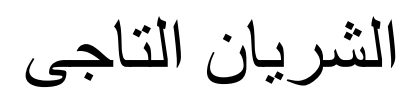

أحمد حمدى عبدالعزيز بيومى، أبويكر الصديق تمام حسين، الحسين مصطقى زهران قسم القلب والاوعية الاموية، كلية الطب، جامعة الازهر

E-mail: ahm.ham.bay@gmail.com

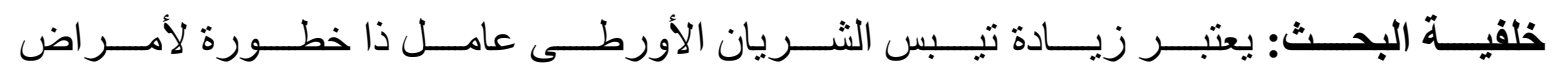

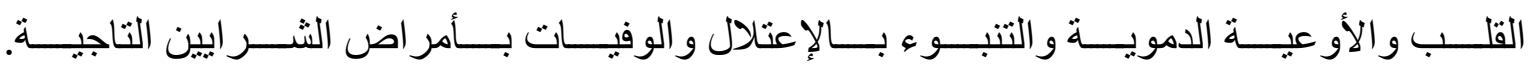

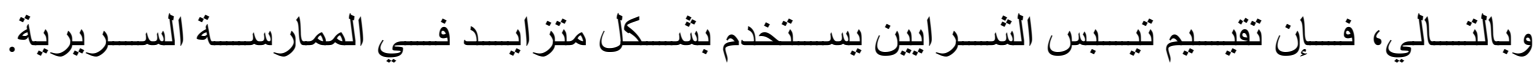

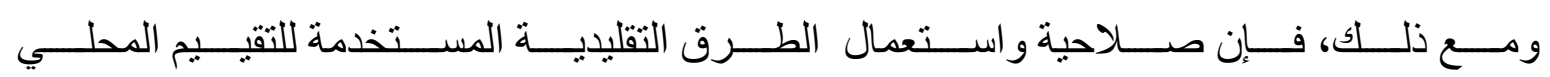

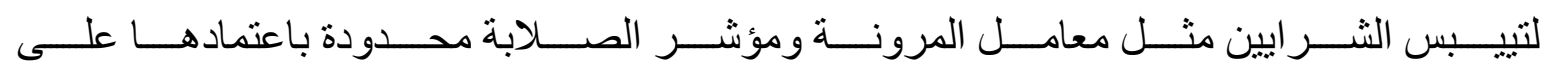

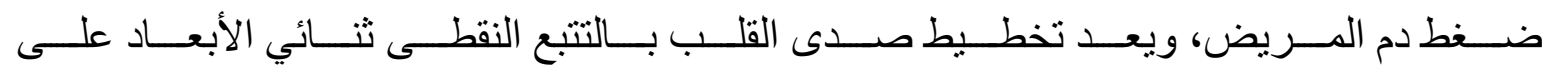

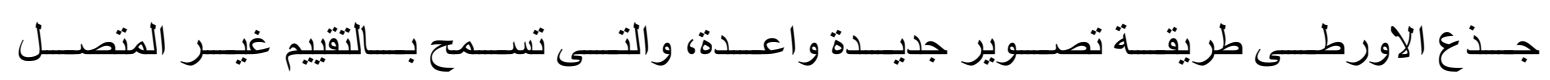
لسر عات الأنسجة.

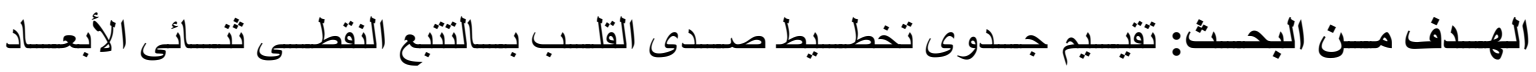

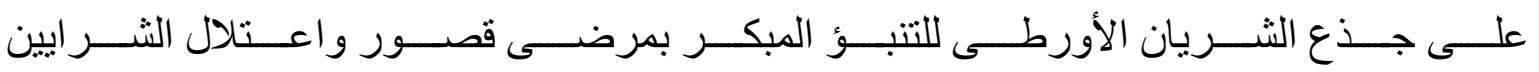

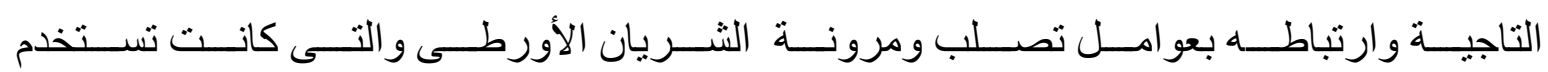
قديما.

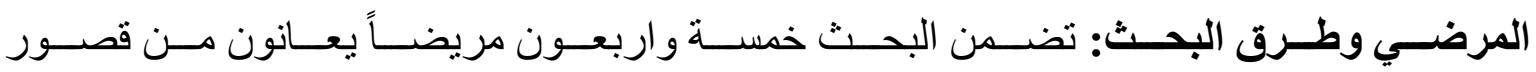

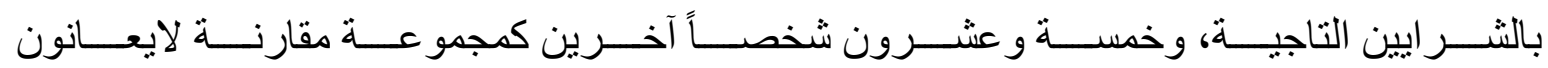

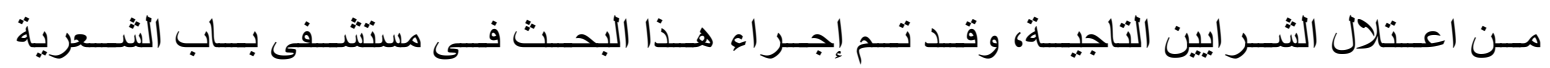

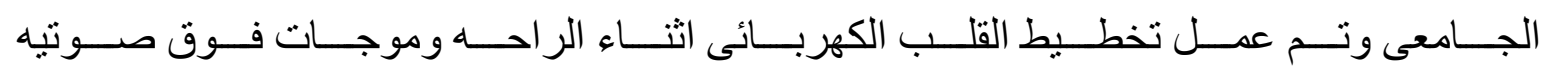

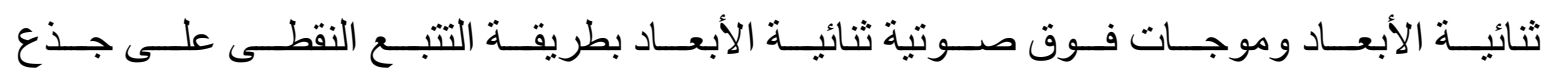

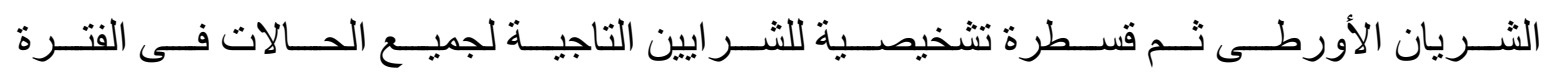
من ابريل 2020 الى أكتوبر 2020. 


\section{CORRELATION BETWEEN AORTIC ROOT STIFFNESS AND...}

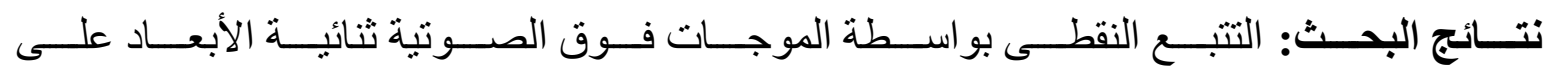

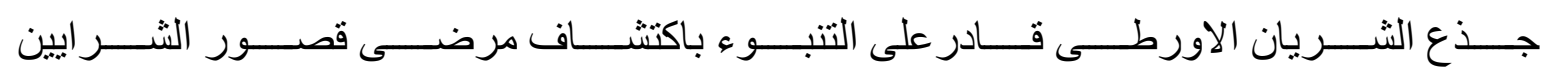

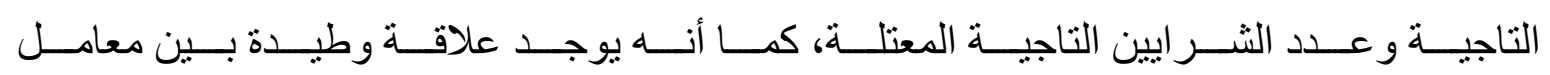

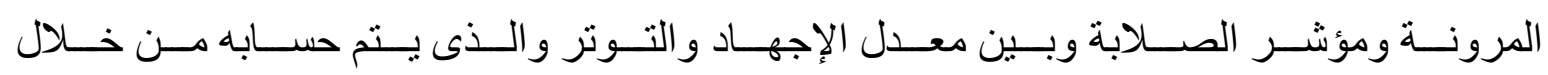
التبع النقطى بالموجات فوق الصوتية ثنائية الابعاد.

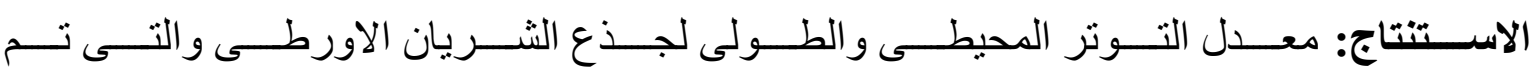

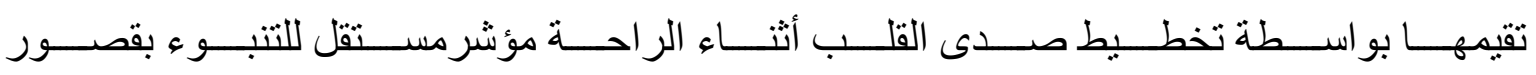
الشر ايين التاجية.

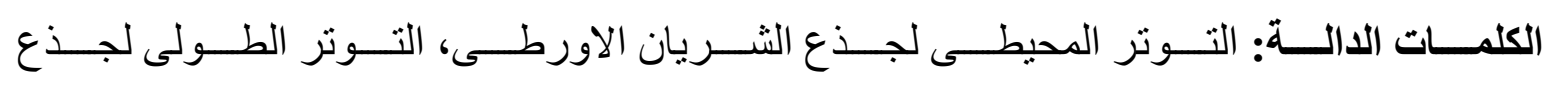

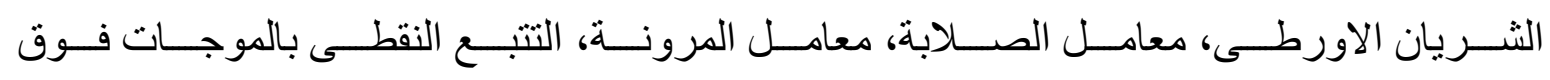
الصوتية ثنائية الابعاد. 